Voix et Images

voixetimages

\title{
Voir ailleurs si j’y suis
}

\section{Jean-François Chassay}

Volume 18, numéro 2 (53), hiver 1993

Francine Noël

URI : https://id.erudit.org/iderudit/201034ar

DOI : https://doi.org/10.7202/201034ar

Aller au sommaire du numéro

\section{Éditeur(s)}

Université du Québec à Montréal

\section{ISSN}

0318-9201 (imprimé)

1705-933X (numérique)

Découvrir la revue

\section{Citer cet article}

Chassay, J.-F. (1993). Voir ailleurs si j’y suis. Voix et Images, 18(2), 394-400.

https://doi.org/10.7202/201034ar d'utilisation que vous pouvez consulter en ligne.

https://apropos.erudit.org/fr/usagers/politique-dutilisation/ 
Roman

\section{Voir ailleurs si j'y suis}

Jean-François Chassay, Université du Québec à Montréal

Transculture, altérité, sont des mots qui reviennent très souvent dans le discours culturel québécois depuis quelques années, mobilisent les discussions et animent les débats. Un ouvrage collectif paru récemment intitulé L'Étranger dans tous ses états. Enjeux culturels et littéraires ${ }^{1}$ indiquait, par la variété des interventions, la prégnance de ce sujet (et d'autres, connexes) dans différents champs intellectuels au Québec. Les questions soulevées par les écrivains québécois d'origine étrangère (et par leurs livres) reçoivent aujourd'hui un intérêt qu'on ne peut nier.

Si de nombreux textes de fiction récents posent sur le Québec un regard qui vient d'ailleurs, on note parallèlement à cela - et peut-être 
est-ce partiellement un effet des précédents - un nombre important de romans qui vont chercher ailleurs le sujet même de leur narration, et qui se situent dans des espaces-temps de plus en plus hétérogènes. L'importance qu'on a accordée depuis quelques années - et particulièrement en fonction de l'anniversaire qui 'se profilait à l'horizon - à la littérature montréalaise a peut-être masqué cette nouvelle réalité. Il s'agit pourtant d'une autre façon de souligner le rapport à l'étranger, notamment en imposant, dans certains cas avec maestria, pour reprendre l'expression de Sherry Simon, *le fantasme de l'interlangue, de la langue plurielle ${ }^{2}$.

\section{Voyage au bout de l'obsession}

C'est le cas en particulier' du premier roman de Rober Racine, Le Mal de Vienne ${ }^{3}$, ouvrage totalement obsessionnel, délirant, marqué par un humour grinçant et où la culture apparâ̂t au cœur d'un maëlstrom dans lequel la langue vient s'abîmer. Il s'agit finalement, on s'en rend compte le livre refermé, d'un roman assez atroce. sur la mort, qui se manifeste ici de différentes manières. Rarement aura-t-on lu au Québec un premier livre aussi maîtrisé, et qui risque de provoquer autant l'admiration d'inconditionnels qu'un sentiment de répulsion chez certains lecteurs. C'est moins courant qu'on ne le croit.

Dans Extinction, son dernier roman ("un effondrement"), Thomas Bernhard fait dire ceci à son narrateur: "Souvent [...], nous nous laissons entraîner à exagérer tellement que nous finissons par tenir cette exagération pour le seul fait logique et ne voyons plus du tout le fait réel, rien que l'exagération poussée à l'extrême ${ }^{4}$." La teneur du roman de Racine tient dans cette phrase et elle n'est pas prise chez Bernhard pour rien, puisque le personnage central du Mal de Vienne, Studd, est atteint de "thomasbernhardovite. Cet homme, entomologiste de son état, subit depuis neuf ans cette étrange maladie qui le voit hanté par Bernhard (son style, ses personnages, etc.). Vivant entre sa mère - femme âgée qui lit chaque semaine sur les ondes de Radio-Canada Béton adagio con sadico et qui a déjà lu Corrections à la télé en 28 minutes - et sa nièce Pauline - qui n'est pas en reste pour ce qui est des idées fixes - Studd ressemble à un cauchemar ambulant. Le roman oscille entre Montréal et Vienne, les personnages de Bernhard et Studd (qui se confondent peu à peu), sans qu'on ne sache toujours ce qui est vrai dans tout ce que le narrateur nous révèle sur l'auteur de L'Origine (a-t-il vraiment fait inscrire sur la tombe de sa mère: "Je ne voudrais pas être à votre place"?). Nous ne sommes plus en pleine guerre du faux (pour reprendre l'expression 
d'Umberto Eco), mais plutôt dans le monde de l'improbable toujours possible. L'ère du soupçon se voit remplacée par l'ère de la fatalité: on ne pourra jamais savoir avec certitude, démêler la vérité du mensonge, et mieux vaut donc perdre tout de suite ses illusions.

Narré par un ami de Studd, Alex, un météorologue - dont la femme, chimiste de son métier, accumule les doctorats et écoute systématiquement Les Beaux Dimanches, sans avoir jamais manqué une émission - Le Mal de Vienne est un roman sans fin, qui ne peut que continuer éternellement à tourner dans sa spirale obsessionnelle et qui se termine, cela va de soi, sur un point d'interrogation.

L'entomologiste Studd s'arrête sur les mots comme sur des insectes, les décortiquant pour mieux les vider de leur sens. Cet homme qui vit pour et par la musique ne cherche-t-il pas d'abord les notes dans les mots? "Réaliser la mission doit façonner le sol des régions utopiques. Ré la mi si do fa sol ré ut. (p. 112). Les mots ne sont plus que magma sonore, bruits plus ou moins harmonieux, sur lesquels la raison vient se briser.

Bernhard n'est pas là uniquement comme figure mais aussi comme discours et, davantage, comme ferment d'une crise des savoirs, du malaise de la culture occidentale aujourd'hui. L'écriture répétitive, musicale, rappelle celle de l'écrivain autrichien. Mais la dilatation de sa prose se retrouve aussi dans ce qui apparait ici comme un "texte listique - (l'accumulation de données d'ordres divers qui s'additionnent de manière délirante). Ceci n'est que la partie la plus visible de ce qu'on pourrait nommer une sorte de catastrophe culturelle. Bernhard n'est qu'un symptôme (accablant, bien sûr) du fantasme de la copie parfaite, de la volonté de faire du psittacisme la forme d'art ultime. Studd imite tel comédien jouant telle pièce à la perfection, les propos tenus par l'un ou l'autre lors d'un événement historique en copiant les voix (il possède des enregistrements de tout). Il est également copropriétaire du Club des Sosies et, lors d'une des scènes les plus réussies du roman, Alex pénètre avec lui dans ce club privé où il compte -treize Herbert Van Karajan [...] vingt-neuf Sophia Loren; dix papes Pie XII, six Lino Ventura, un groupe d'au moins trente Édith Piaf à vingt ans, quatorze Churchill de la fin, cinq J. F. Kennedy " (p. 152), etc. Les duplicata sont mieux que les originaux: ils sont plus. Studd va jusqu'à s'exclamer: * Plus tu vois un nombre élevé d'objets identiques, d'insectes identiques, d'animaux identiques, de sosies identiques, plus l'écœurement s'installe en toi. La quantité fait peur et séduit " (p. 140).

Voilà que dans ce roman où une polyvalente montréalaise se nomme "Polyvalente Alice Cooper", la culture ne veut plüs rien dire 
parce qu'elle ne repose plus sur la mémoire et le savoir mais bien sur la plus complète redondance. Par la voix des personnages du roman, toute la culture se dit, s'expose, mais ce fantasme d'appropriation ne laisse aucune place à la connaissance. Les discours culturels sont juxtaposés, confrontés les uns aux autres. Mais cette accumulation, désordonnée, renvoie de manière complaisante la culture à la culture (une pièce musicale rappelle une pièce de théâtre qui rappelle une autre pièce musicale qui rappelle un livre, etc.) sans jugement critique, avec une sorte de narcissisme démoniaque dans lequel Studd se voit enfermé.

Rien pourtant dans ce roman de la thèse ou du discours apocalyptique sur la fin de la culture. Au contraire un texte assez festif, très drôle par moment, dont les pages précédentes ne peuvent rendre compte que de manière bien modeste, tant il y aurait à dire. Paradoxalement, le spectre grinçant de Thomas Bernhard apparait dans ce contexte comme le contrepoids de ce que vit (et de ce que représente) Studd. Dans l'Autriche bien policée de l'après-guerre, il symbolise à l'envi l'esprit critique, le travail intellectuel d'un homme qui a cherché toute sa vie justement à réveiller une mémoire qu'on voulait oblitérer. Bernhard représente tout à fait le refus implacable d'une égalisation de la culture qui conduirait à tout mettre sur le même plan et à tout relativiser. Studd est obsédé par un écrivain qui représente en bout de piste l'envers de sa propre personnalité. L'horreur d'un certain conservatisme qui préfère taire les choses plutôt que de les analyser, qui juxtapose pour mieux annihiler ce qui dérange, dénoncé par Bernhard, correspond au versant réaliste en quelque sorte du délire effroyable de Studd, ânonnant la. culture (toute la culture) et exprimant par son discours ce que Joyce déclarait naguère: «music-hall, not poetry, is a criticism of life.»

\section{Filiation}

Le "mal de Vienne" apparaît sous un autre jour dans le dernier roman de Lise Lacasse, Avant d'oublier's. Après avoir vécu à Londres son enfance et son adolescence avec sa mère, qui finalement se remarie et déménage en Californie, Cathie, la narratrice, part pour Paris où elle fera sa vie. C'est là qu'un jour, alors qu'elle a déjà 22 ans, elle reçoit une lettre de son père qui habite Vienne et qu'elle n'a jamais vu. Cet homme viendra obnubiler ses pensées pendant plus de vingt ans.

Le roman s'ouvre sur la mort du père de Cathie qui se remémore par la suite, dans un ordre respectant, mutatis mutandis, la chrono- 
logie, les événements marquants de sa vie. C'est d'abord cette relation ambiguë avec son père, qu'elle ne voit presque jamais (une fois par année environ, à partir de l'âge de 22 ans), relation allant plus loin que la simple affection filiale, qui forme le nœud du roman. Que faitil et comment vit-il? Les informations qu'il donne à sa fille demeurent vagues: un jour elle croule sous les cadeaux qu'il apporte et six mois plus tard il écrit pour lui emprunter un assez fort montant d'argent, sous prétexte que certains investissements ont mal tourné. À sa mort, elle apprendra avec amertume ce dont le lecteur se doute depuis longtemps: son père a fait de sa vie un spectacle, inventant des voyages et des fortunes pour mieux masquer la grisaille d'une vie somme toute assez banale.

La fascination qu'on peut ressentir face à ce personnage vient de sa volonté de se dépenser sans cesse, de broyer l'ennui de la vie en créant l'illusion d'une énergie folle, nécessaire pour cumuler ses multiples activités. Si le père de Cathie ne manque pas d'un certain attrait romanesque cependant, il ne suffit pas à maintenir l'intérêt du lecteur tout au long du roman. L'écriture manque de relief et, surtout, le ton psychologique adopté ne parvient pas à relancer le mystère du personnage et l'ambiguité de la relation entre le père et la fille. Les amants de Cathie défilent entre deux séances chez l'analyste ou deux crises existentielles. Ses tracas divers, qu'elle assène au lecteur, finissent par lasser.

On peut s'interroger également sur les raisons qui ont décidé l'auteure à situer son roman en Europe. Née de père autrichien et de mère norvégienne, Cathie grandira à Londres avant d'aller vivre à Paris et verra sa mère épouser un Américain de qui elle aura une fille, la demi-sœur de la narratrice. Ce croisement de différentes cultures n'est pourtant jamais un enjeu du texte. Ni les générations, ni les langues, ni l'appartenance à une ville, à un pays, ne sont à proprement parler sources de tensions dans ce roman. La personnalité des uns et des autres se forme en-dehors de toute considération culturelle, ce qui rend fort artificiel le cadre spatio-temporel dans lequel le roman se développe.

\section{Déracinement}

Deux ans après l'excellent Collier d'Hurracan ${ }^{6}$, Louis Lefebvre publie Guanabani ${ }^{7}$ qui reprend une problématique similaire, à savoir les tensions culturelles entre des Blancs européens et des communautés d'Amérique. Son premier roman se situait à la Barbade en 1832 , celui-ci dans l'Espagne de la fin du XV' siècle. Atobeian, prince 
de l'île antillaise de Guanahani, s'est retrouvé en Espagne, "invité " par les conquérants (en l'occurrence, plus précisément, Christophe Colomb), comme preuve de leur passage sur des territoires éloignés. Après de nombreuses années, il s'échappe pour se réfugier dans les murs d'un monastère isolé où il va dicter, en toute liberté, ses mémoires à Fray Bartholomé. Ce sont ces mémoires que donne à lire Guanabani.

Atobeian pose sur la société espagnole un regard d'anthropologue, notant aussi bien ce qui le fascine que les aberrations de cette civilisation qui est tout à fait étrangère. Le regard est ici le mode de savoir privilégié: Don Hernan, chez qui il habitera de nombreuses années, affirme l'envier: "Tout ce que tu vois ici, tu le vois avec des yeux neufs, tel un enfant qui naîtrait tout formé et muni de l'entendement d'un homme mûr. Quel opium exquis contre l'ennui!» Mais le regard peut également être source de déception: "J'attendais tellement de choses du regard des Blancs[,...] qu'on écarquille les yeux sur mon passage et qu'on s'émerveille de ma différence ", déclare Atobeian qui découvrira plutôt, devant lui, très rapidement, une morne indifférence.

Les propos d'Atobeian prennent inévitablement un tour comparatif qui devient à la longue un peu mécanique. La perspective adoptée ici par Louis Lefebvre - le narrateur dicte ses réflexions à un scribe qui n'a pas le droit de l'interrompre - enferme le roman dans un monologisme qui le dessert. La critique du monde espagnol se voit opposée à l'ancien mode de vie, celui vécu sur l'île, qui se rapproche d'une représentation originelle, paradisiaque, face à laquelle la civilisation européenne ne pouvait que déchoir.

Il est symptomatique que les passages les plus intéressants du roman soient justement ceux où Atobeian relate ses échanges avec don Hernan. Les échanges qu'ils entretiennent au fil des années instaurent une véritable confrontation entre deux conceptions de la culture. La relation entre les deux hommes est vraiment vécue sur le mode de l'altérité et la tension qui en résulte fonde une réelle dynamique romanesque. Malgré les qualités indéniables du texte (érudition, sens de la narration), le reste du monologue d'Atobeian s'empêtre un peu trop souvent dans le didactisme.

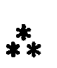

Il existe peu de points communs entre ces trois romans, et pourtant ils trouvent tous trois leur sens dans un même rapport à l'autre, une même altérité radicale qui échappe à la société québé- 
coise dans la mesure où cette dernière n'est pas au centre de la problématique romanesque. Peut-être y a-t-il ici les traces d'un nouveau courant en train de se dessiner et dont on pourrait sans doute trouver de multiples exemples dans la production des dernières années.

1. Simon Harel (directeur), L'Étranger dans tous ses états, Montréal, XYZ éditeur, coll. -Théorie et littérature •, 1992, 190 p.

2. Sherry Simon, "La traduction inachevée, L'Etranger dans tous ses états, op. cit., p. 27.

3. Rober Racine, Le Mal de Vienne, Montréal, l'hexagone, 1992, 194 p.

4. Thomas Bernhard, Extinction, Paris, Gallimard, 1990, p. 385.

5. Lise Lacasse, Avant d'oublier, Montréal, Trois, 1992, $178 \mathrm{p}$.

6. Louis Lefebvre, Le Collier d'Hurracan, Montréal, Quinze, 1990.

7. Id., Guanahani, Montréal, Boréal, 1992. 